\title{
NEWS ANALYSIS
}

All articles written by David Simpson unless otherwise attributed. Ideas and items for News Analysis should be sent to David Simpson at the address given on the inside front cover.

\section{Uzbekistan: who's in charge now?}

The disintegration of the former Soviet Union into separate nation states was accompanied by an unruly stampede by the transnational tobacco companies, falling over themselves to buy up the formerly state owned tobacco factories. Was it just the opportunity to take over going concerns at knock down prices, or more the chance to get into markets that had been denied them up to that time? Or was the most attractive feature the already high smoking rates, resulting from years of negligible health education and the implicit promotion of tobacco as an essential part of human existence, which along with alcohol was used as a regulator of cash in the economy? All these were no doubt obvious attractions at the time, but there is another which, at least to observers in the health professions, is only now beginning to be fully understood.

When companies such as British American Tobacco (BAT) moved into the countries euphemistically known as the new democracies of Europe, they were, in actual fact, moving into cultures little changed from the former Soviet times. They were buying not only the factories, the markets and the labour, but passports to unfettered action as well. For while these nations' economies were quickly transformed from the former "socialist", centrally planned economic systems into market economies, the culture that accompanied them remained-and continues to remain-remarkably intact. Power controlled by a small, mostly unelected elite, protected from criticism and lionised as economic saviours; an almost total freedom of action, with no real accountability for the consequences; and censorship of the news media: these were among the old, "red" culture's distinctive features. Ironically, if the actors have changed, the basic scenery and script remain largely recognisable, and the very infrastructure that barred the way of the tobacco companies in the past is turning out to be among the most valuable things the new "brown elite" has acquired.

Uzbekistan provides a striking example. It is a large nation, dwarfing several western European countries. It is over three times the size of England, but with only half the population; just the tragically ruined and polluted area of the Aral sea, which lies within it, is one and a half times the size of Denmark. To BAT, no doubt, Uzbekistan is first and foremost a large, ready made market. Of its 25 million inhabitants, many are already smokers, most having picked up their addiction in Soviet times. But there is still scope for more to get hooked, and especially for women to catch up with the men. Perhaps most salivating of all to a tobacco salesman is the fact that over half the population is under 15 years of age. Health organisations are well aware of the burden of disease that already results from past smoking, of course, but feel virtually powerless to do anything about stopping its inexora-

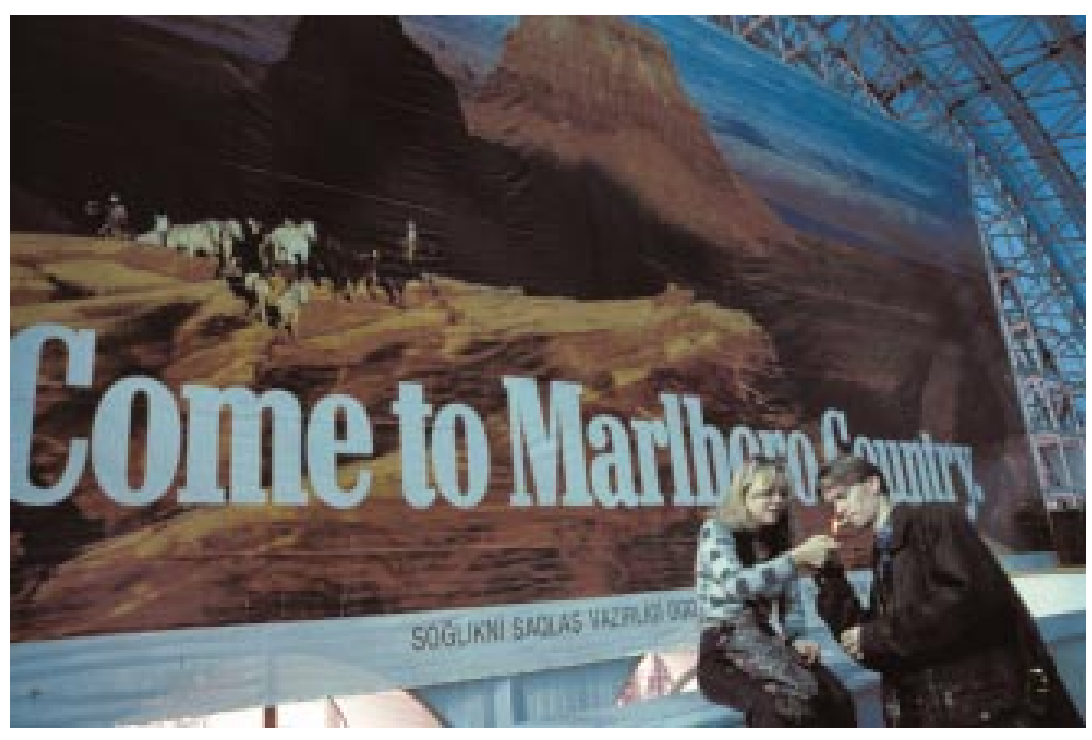

Cigarette advertising in Tashkent, Uzbekistan.

ble rise in the future. It is not only a question of the relative lack of power compared to massive transnational companies which have bought their country lock, stock and ashtray, but an absurd imbalance of resources.

True, the country passed a tobacco control law, but it was never implemented. Admittedly, when tobacco control experts from the World Health Organization were due to arrive in 1997, the health ministry reckoned it had better have a tobacco programmes coordinator, so it appointed one, a busy cardiologist. $\mathrm{He}$ did his best, which was better than the nothing the ministry had done before, but in fairness, having no salary for the extra job thrust upon him, and no budget to spend, it was clear from the outset that there was little he could achieve. When he stepped down from the role (though diligently continuing his anti-tobacco efforts in his clinical work), a successor was appointed, but still without salary or budget. When the monthly salary required to fill such a post is probably less than a tobacco company pays to fill the fuel tank of just one of its promotional vehicles-US\$15-20 per month-is it really beyond the reach of the government to spend such a sum on starting to tackle the country's tobacco problem? 
Contrast this situation with what the WHO delegates found when they arrived at the capital, Tashkent. While they, accredited WHO representatives as they were, had to wait three hours in different lines to be processed by immigration and customs, they saw someone who was able to walk freely through the immigration area to identify the people he was meeting, whom he then simply invited to follow him VIP style through to the waiting transport. The nature of his pass for being able to exercise such privileges? A sign with BAT's name and tobacco leaf logo. Another representative of the brown elite was waiting with a sign bearing RJ Reynolds's name.

The team from WHO noted that BAT had been attempting - and apparently succeeding - to buy goodinstitutions; for example, it paid for a modern clinic in Samarkand, site of its main plant. Perhaps more remarkable, they found other health institutes which had been offered money by BAT, but whose desperate need for funds was matched only by the integrity of their leaders. Such heroic acts usually go unsung.

The WHO delegates also heard talk of a contract between BAT and the government, limiting the antismoking measures the government mum to be spent at less than $\$ 15$ per month? They saw a massive amount of tobacco advertising-ubiquitous billboards, whose mild health warnings in small print at the bottom was impossible to read from any distance. According to their report, there were will by giving money to health care could take- perhaps it fixed the maxi-

numerous cigarette brand window signs and promotional awnings over shops, as well as a plethora of high quality plastic bags bearing tobacco ads. In a sort of tobacco advertiser's fantasy fulfilment, these bags were not only being used as shopping bags by the general population, but as briefcases by medical students. As in neighbouring countries such as Kazakhstan (see Tobacco Control 2000;9:269), BAT is busy with a much flaunted but worthless youth education programme, which probably enhances the adult allure of cigarettes for the next batch of "starters".

Is the tobacco industry's exercise of power limited to more or less unfettered advertising and shady guarantees not to impede its sales by health promotion? With the sort of culture described above, which includes some of the secrecy of the former regime, it is hard to be sure, but all too easy to guess. For example, under the new constitution, Uzbekistan is supposedly free from the censorship that was routine in Soviet days, yet in reality, the apparatus of censorship still trudges on and little has changed except those being protected by it. Only this year, senior editors of a newspaper that had accepted a hard hitting story about the country's tobacco problem felt it wise not to publish it before lengthy sessions with the censors, conceding several cuts and changes along the way.

A few years ago, a less overt attack on tobacco in the news media resulted in some responses in kind: the sort where a few paid hacks were cranked

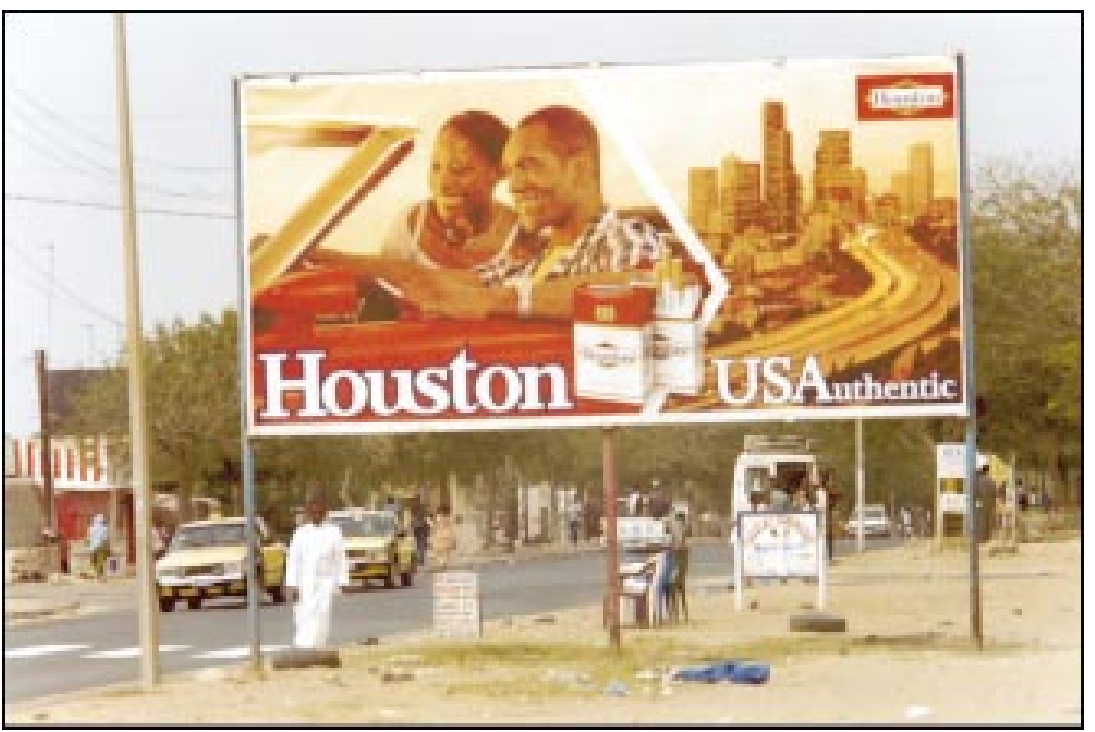

Sénégal: a billboard forming part of the launch of Houston brand in the summer. Multimedia advertising included a fleet of all terrain vehicles servicing promotional events. As with other cigarette promotion in the country, American associations are central to the brand's image. A much repeated radio advertisement, to a background of rock music, said: "This taste, this force, this cigarette . . Houston, USA authentic." The launch was held in May and fune. The summer school holidays begin in Fune.

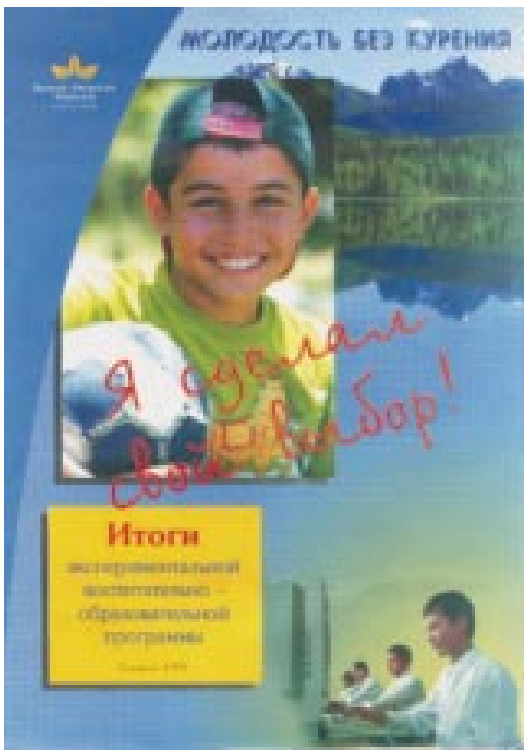

Brochure promoting BAT's youth education programme in Uzbekistan. One of the co-sponsors is the Ministry of Public Education.

up to write pieces with headlines like: "BAT is ours!" (reminiscent of patriotic utterances by the party hacks of the past, the Russian version scans); and advice that it is better not to smoke, but if you do, then at least smoke good quality (code for western) cigarettes. This time, however, Uzbek readers were spared this sort of nonsense, though some observers still fear delayed and perhaps hidden retribution.

In Soviet times, state interference in the press would not only have been perceived by the general population as routine, but journalists whose work was censored might even have seen it as a reassurance of integrity, the inevitable result of criticising the corrupt elite, possibly presaging eventual adoption by INDEX on Censorship. In modern Uzbekistan, it remains to be seen whether the abuse of power to protect the all powerful brown elite will become accepted as equally routine and inevitable.

Mathew Arnold's classic narrative poem Sohrab and Rustum ends by following the course of the Oxus river, beside which Rustum has unwittingly killed his long lost son in a duel of champions from opposing armies. The poem ends as the river struggles through miles of obstructions, "till at last/ The long'd-for dash of waves is heard, and wide/ His luminous home of waters opens, bright/ And tranquil, from whose floor the new-bathed stars/ Emerge, and shine upon the Aral Sea." The Soviet Union so abused the Aral and diverted its tributaries, and allowed massive amounts of industrial pollution to end up in it, that it is now just a vast, dry, toxic 
wasteland, whose poison dust blows into neighbouring countries. If anyone questioned what was going on while this scandalous and irreparable environmental disaster was taking place, no doubt they were told the harm was greatly exaggerated, and reminded of the economic benefits of industrial progress. Unless the current government acts fast, and strips the tobacco industry of its extraordinary privileges, a comparable disaster will take place in the human landscape over the next quarter of a century, this one measured in tens of thousands of needless premature deaths.

\section{Hungary: the complete consumer service}

As in Uzbekistan, BAT is not neglecting health in Hungary, which has among the most serious smoking epidemics in the world. In the medieval city of Pecs, home to its main factory, it has sponsored just about anything that is prepared to take its money, presumably in the hope of buying the maximum amount of silence about its Hungarian activities for as long as possible. For example, it funds a hostel for homeless people, now called BAT House, and the BAT Theatre. It has paid for a television studio and equipment for the local university's media centre (though in return, it wants the university to scrap its indoor no-smoking policy, to create a "cultured atmosphere" for students who smoke). But most thoughtful of all is a state-of-the-art clinic, by far the best equipped in the country, complete with the sort of whole body scanning apparatus so useful for finding the exact site of tobacco induced tumours.

\section{Gambia: hey, big boy!}

Among the more telling gaffs by tobacco company employees recently was one heard in the Gambia by a team from the British Broadcasting Corporation (BBC). They found BAT and its Benson and Hedges brand hard at it with teenagers at a beach volleyball tournament. The organisers told the $\mathrm{BBC}$ it was laid on during the school holidays for local youths ["young adults", surely?-Ed]. Yellow B\&H banners were everywhere, as were young women in $\mathrm{B} \& \mathrm{H} \mathrm{T}$ shirts handing out free cigarettes among the crowd. Like all the big tobacco companies, BAT claims it does not give samples to children under 18 , but the women were lighting up cigarettes for youngsters, many of whom looked distinctly under age to the BBC crew, and no-one was checking their age. On being questioned about this, a BAT representative said the age limit was only 15 , before quickly correcting herself, and adding: "We only give free cigarettes to big boys."

\section{Pakistan: that boat again}

BAT has learned little from having its John Player Gold Leaf ocean going sailing boat banned in Bangladesh and declared navicula non grata in Sri Lanka (Tobacco Control 2000;9:9,129). Continuing its marketing of addictive and carcinogenic products by associating them with the healthy, exciting sport of ocean racing, whipping up a frenzy of advertising and sponsored events for young people at ports of call, the "Voyage of Discovery" arrived back in Karachi in September. It had already visited the city, the largest in the country, on its way east the previous year, and free cigarettes were handed out to an estimated 10000 youngsters at promotional events. This time Pakistani health advocates decided to go to court, inspired by legal success in Bangladesh and assisted by colleagues there (Bangladesh was formerly East Pakistan). While not getting a ban in time to stop the visit, they did achieve two important gains.

First, the event galvanised concerted action by medical and health groups in a way that numerous tobacco control lectures and workshops had failed to do in the past. Most importantly, it bought the Pakistan Medical Association out fighting, taking an important lead in the court action, and helping to create an ad hoc coalition of a wide range of medical specialists and people from other disciplines. The ultimate result of the court action is still awaited.

Second, this time the publicity surrounding the event was not all one sided. Certainly BAT's gift of Rs4.5 million (US\$77 000) to Radio Pakistan for a live broadcast of the climax of the visit, a concert for young people at the city's most prestigious yacht club, helped to generate favourable publicity. However, several newspapers and other media gave detailed coverage to the health arguments against the visit, and a multidisciplinary doctors' group addressed a major press conference. BAT even felt obliged to trot out the almost irrelevant assurance that it would exclude under-18s from the big event (thereby making it even more attractive to the young).

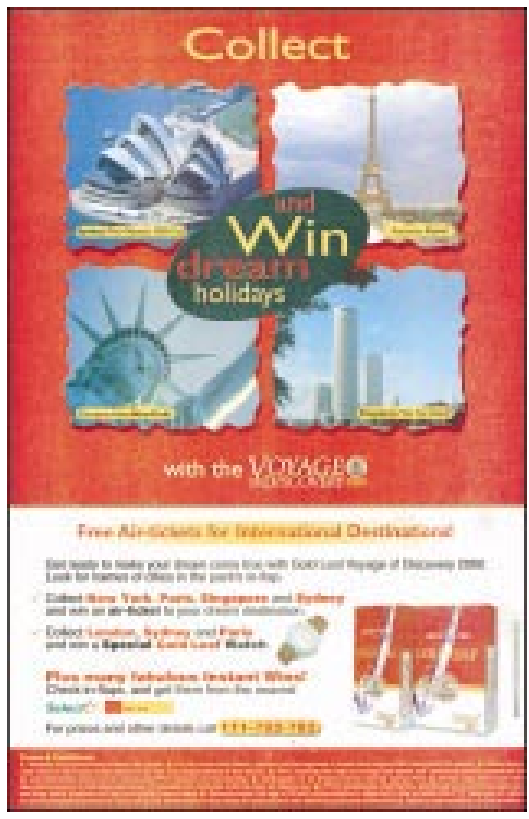

An advertisement for Gold Leaf cigarettes in a Pakistan newspaper, linked to the "Voyage of Discovery" and related promotional activities by $B A T$.

And perhaps there were benefits in the event not actually being stopped, as the newly coordinated health advocates put in hand an elaborate network for capturing a record of as many of the promotional activities as possible. These should prove invaluable in the future, whenever BAT repeats its assurances that it does not promote cigarettes to youth. It's an ill wind ...

\section{SE Asia: Rockefeller's new programme}

"Asia cannot afford to repeat the North American cycle of tragedy from tobacco company aggression. In truth, hundreds of millions of Asians alive today depend on what you do today ... against tobacco." These were the words of Dr Prakit Vateesatokit of Thailand, as he received one of the first Luther Terry Awards for outstanding achievements in tobacco control, at the world conference in Chicago in August.

One response to the challenge is being provided by the Rockefeller Foundation, which has pledged up to US $\$ 10$ million to support proven approaches to tobacco control in Thailand, Malaysia, Cambodia, and Vietnam. The "Trading Tobacco for Health" initiative comes just over 10 years after several Asian markets, including Thailand's, were forced open to US cigarette imports.

By passing strong tobacco control policies and by active non- 
governmental efforts to reduce smoking, Thailand has lowered smoking prevalence over the past decade. Campaigns to raise public awareness of the damage to health from tobacco, and the establishment of a Health Promotion Foundation have set an example for the developing world. The Rockefeller programme will benefit from the regional expertise this experience has developed.

While it is reassuring that Thailand's expertise will be utilised, the juggernaut of "free trade" is descending on Asia as China enters the World Trade Organisation and a number of free trade agreements, such as the ASEAN agreement, come into play. The Rockefeller Foundation recognises the need to invent new strategies, not just globalise those tested in developed countries. Further, it says: "the challenges ....include maintaining sustained commitments over a long time horizon, developing programming that bridges public health with other sectors, and investing in low cost interventions appropriate to the context of developing countries."

Thailand and South East Asia are at a crossroads. Proven local programmes can be expanded and improved if funds are used in a timely manner. Tobacco control resources are very low in Asia, where countries' economies are still weak from the 1997 financial crisis. There is a need to accelerate resource mobilisation smoking, increased excise taxes on and boldness of innovation in tobacco control programmes, especially in view of the expected impact of trade agreements, tobacco industry spendtion". Hence the great potential of the Rockefeller initiative. The hope is that Asian tobacco control advocates will be able to prevent the repetition of some of the western cycle of tragedy by not repeating failed tobacco control approaches, thus preventing millions of deaths from the brown plague.

STEPHEN HAMANN Tobacco Control Policy Research Network Bangkok, Thailand slhamann@hotmail.com

\section{Canada: warnings with colour pictures required}

Following a lengthy regulatory process, Canada's new cigarette package warnings are the first with photographs, and the first covering $50 \%$ of the package front and back.

The content of the new warnings was finalised on 26 June 2000 when the cabinet of the Canadian government adopted the Tobacco Products Information Regulations under the Tobacco Act. Before adoption, the regulations had received unanimous approval by the House of Commons Standing Committee on Health, following public hearings, and by the House of Commons as a whole. ing and tobacco industry "consolida-

Considerable research and other work by the Canadian Department of Health and by health organisations contributed significantly to the development of the regulations.

The regulations require that one of 16 rotated picture based warnings, in full colour, cover $50 \%$ of the top of the front and back of the package, with English on one side and French on the other.

Inside the package, one of 16 additional messages is required, either on an insert, or on the "slide" portion of slide and shell packages. Nine of the interior messages emphasise quitting advice, while seven focus on health effects. The interior messages - which are text only and in black, yellow, and white - contain a web address for further information. The interior messages are a world precedent.

The required messages are reproduced on the web site of Health Canada (the ministry of health).

For cigarette brands with more than $2 \%$ market share, altogether representing about $60 \%$ of the cigarette market, the new exterior warnings are required by 23 December 2000 at the manufacturer level. For other cigarette brands, and for other tobacco products, the new labelling requirements come into effect 26 June 2001 .

On the side of the package, a range of yields of tar, nicotine, carbon monoxide, formaldehyde, hydrogen cyanide and benzene must be displayed. The lower end of the range is based on the ISO test method, with the upper end based on a modified ISO method

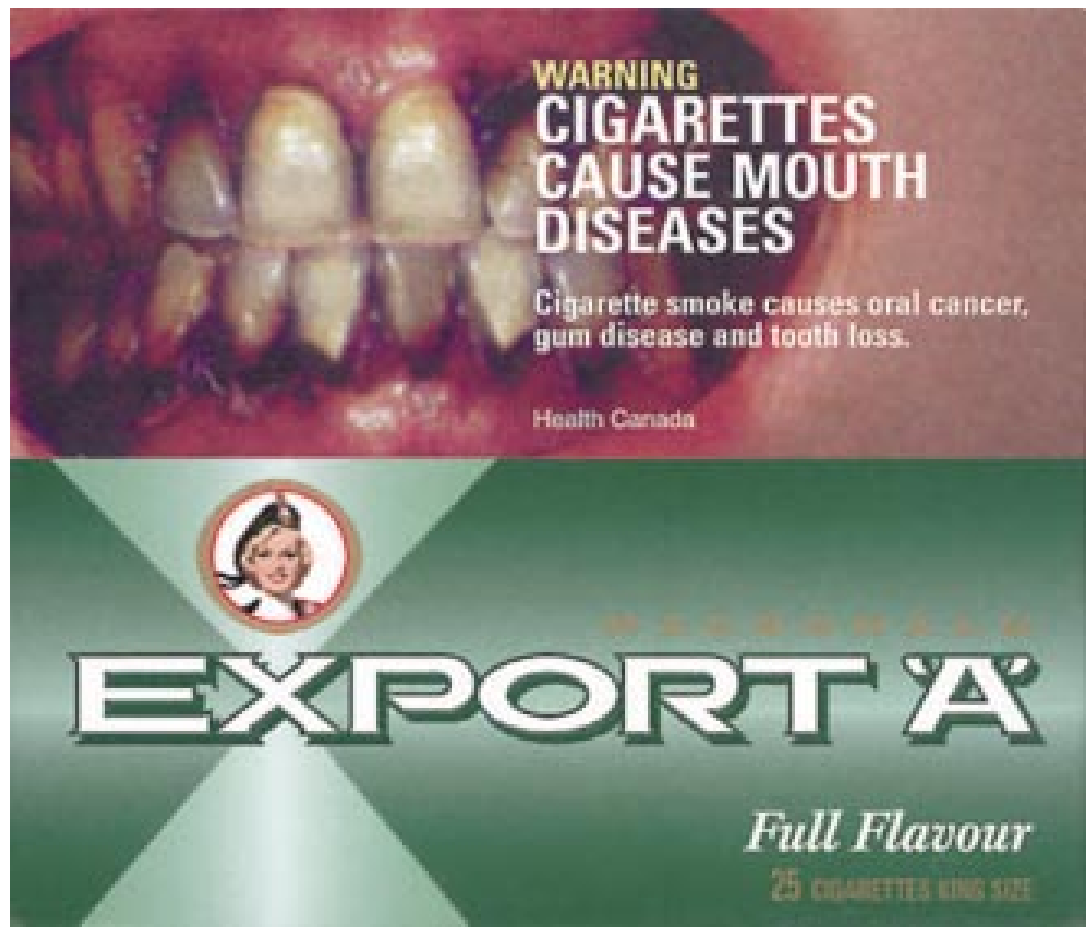

A mock up package with one of the new exterior warning (left) and one of the package inserts (right).
You CAN quit smoking!

Tobacco products are highly addictive

Set a definito quit date. You noed to know what day will be vour first as a nen-smoker.

Take it one dery at a time. Wake up and tory to yourself," "I choose not to smoke today."

Keep yourself active and busy.

Try this coping strategy - remember the 4D's - Delay smoking for ten minutes, sake a Deep breath or two, Drink water and $D_{0}$ something else - distract yoursolf.

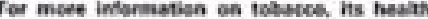

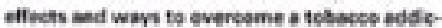
tion bas is a doeter, nurne of pharmatiat of vilt nww isfotobecca.eem 


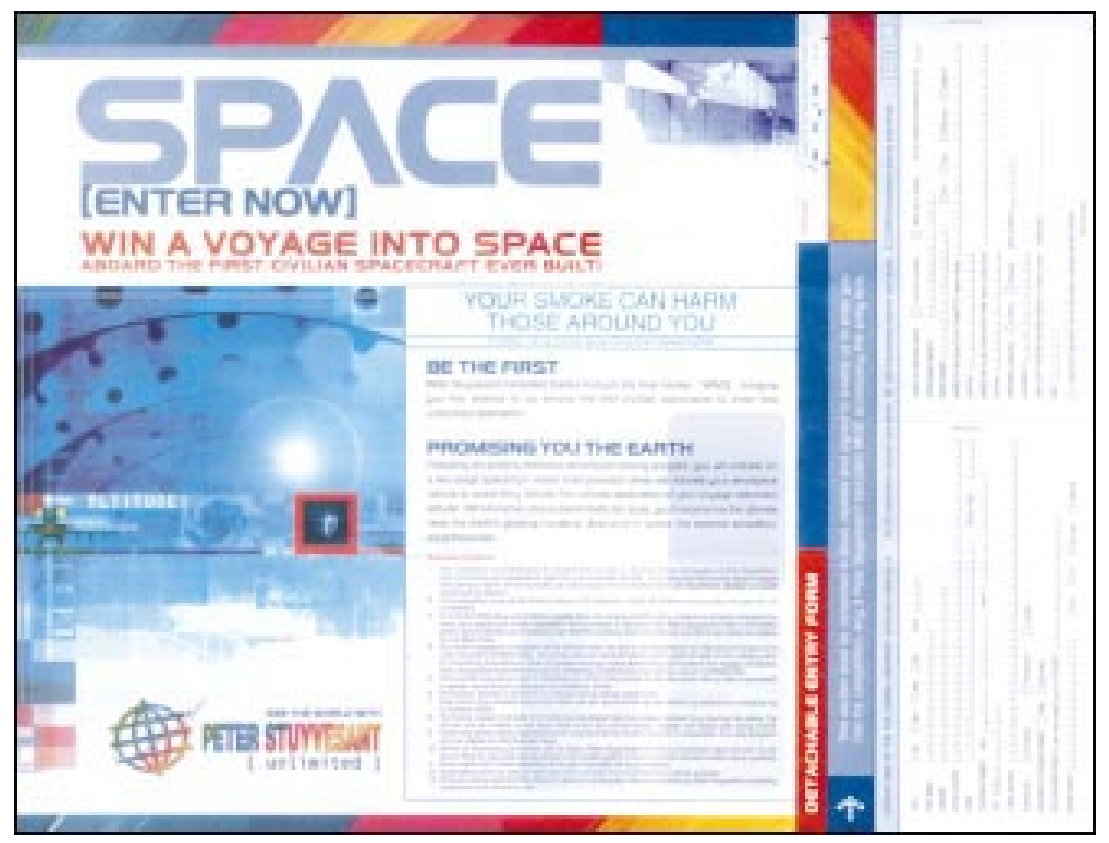

South Africa: an entry form for the Peter Stuyvesant "Spaceflight" competition run during 2000. All entrants, who had to submit bar codes from three packs of the sponsor's cigarettes, were entitled to win a cigarette lighter and a place in a weekly draw for a Palm $111 \mathrm{c}$ palmtop computer. The overall winner is to be given a place on the first commercial space voyage, target date 2003. It is thought the fight will be strictly non-smoking.

to take into account smoker compensation. Requiring a range of yields is a world first, as is requiring yields for six substances.

The warnings for cigarettes are also required on packages of roll-your-own tobacco, tobacco sticks, kreteks (Indonesian style clove cigarettes), and leaf tobacco for retail sale. On cartons, including for cigarettes, picture based warnings are required on $50 \%$ of all six sides. For packages of cigars and pipe tobacco, one of four rotated picture based warnings is required. For packages of smokeless tobacco and bidis, one of four text only warnings is required.
Following adoption of the regulations, tobacco manufacturers filed a legal challenge, arguing that the regulations: (1) expropriated their packages; (2) were unauthorised by the Tobacco Act; and (3) were an unjustified infringement of constitutional protection of freedom of expression. The companies applied for a preliminary injunction to block implementation of the new warnings pending the outcome of the trial, but on 20 September 2000 Justice Danielle Grenier of Quebec Superior Court dismissed the application. The manufacturers announced they would not appeal and would comply with the
December deadline. Manufacturers had previously argued that printing the colour warnings was not feasible, a desperate, incredible, and fortunately unsuccessful argument.

ROB CUNNINGHAM Canadian Cancer Society rcunning@ottawa.cancer.ca

\section{UK: disarming truth about NRT}

The success of nicotine replacement therapy (NRT) in smoking cessation is affected by the patient's understanding of how to get maximum benefit from the device, hence the importance of counselling. But there are some things that even the most seasoned counsellors may omit to mention, on the grounds that it is fair to assume the user already understands them. Staff at a smoking cessation clinic in London, UK, recently encountered a patient who was trying to stop smoking with the help of a nicotine patch, but reported feeling no benefit from it. Further gentle counselling was called for when it turned out why. She had been wearing the patch on the sleeve of her coat.

\section{Our cover}

Our cover this issue features an original painting titled One Lung by Phoenix, Arizona artist Mr Albert Ortiz. Mr Ortiz, now in his 70s, has produced a series of paintings which he hopes will discourage smoking. Some of these may be found on his website (http://members.tripod.com/ NoSmokingArt/). He welcomes use of these for educational purposes. 